\title{
Customer Analysis Using Business Buying Behavior Framework to Develop a B2B Marketing Strategy for User Experience (UX) Studio, Uxgala
}

\author{
Siti Khumaerah Mufti and Atik Aprianingsih
}

\section{ABSTRACT}

\begin{abstract}
Digitalization in Indonesia is rapidly increasing due to the level of active internet users, putting Indonesia as one of the most potential digital markets in the world. This phenomenon also raises the demand and opportunity for User Experience (UX) studios, such as Uxgala, to be involved in digitalization by providing the start-up a UX development service for the digital product.

Unfortunately, Uxgala as a newcomer to the UX development business still has a low reputation and weak competitive advantage. Meanwhile, many competitors and substitutes are also crowding the market. This situation is then intensified by market conditions that have not fully realized the importance of user experience.

In this research, the marketing strategy development was based on the customer analysis through direct interview and indirect observation method, using business buying behavior framework. The study shows that different markets have different needs for UX development services and dissimilar behavior in the purchasing decision that Uxgala can use to strengthen its market targeting and brand positioning. Moreover, developing the 7P's marketing mix that suits the targeted market and also strongly performs the brand positioning.
\end{abstract}

Keywords: B2B Marketing, User Experience (UX) Business, Business Buying Behavior, Customer Analysis.
Submitted : December 12, 2021

Published : January 22, 2022

ISSN: 2507-1076

DOI: $10.24018 /$ ejbmr.2022.7.1.1198

\section{Siti Khumaerah Mufti*}

Bandung Institute of Technology, Bandung, West Java, Indonesia.

(e-mail: siti_khumaerah ${ }^{@}$ sbm-itb.ac.id) Atik Aprianingsih

Bandung Institute of Technology, Bandung, West Java, Indonesia.

(e-mail: atik.apri@ ${ }^{\circledR}$ sbm-itb.ac.id)

\section{INTRODUCTION}

\section{A. Background}

Indonesia was in the first place as the country with the most active internet users since 2017. During the coronavirus pandemic, the average user spent $27 \%$ of daily waking hours on mobile in April 2020, up 20\% from 2019 (App Annie, 2021), making Indonesia one of the most considerable digital market potential countries in the world. Moreover, according to the Global Startup Ecosystem Report (GSER) published by Startup Genome (2021), Jakarta ranked second out of 100 cities worldwide on the list of emerging startup ecosystems in 2020. It was expected to rise even further by 2025 with $18 \%$ $36 \%$ economic growth (Daily Social, 2020). These data illustrate a glimpse of Indonesia's digital power and vast digital industry that awaits Indonesia and all the players involved, including the startup players.

On the other hand, the rise of the internet and digital has shifted the balance of power away from producers to consumers. Companies respond to this change by creating a positive experience to keep the user's delight while using the digital product, involving User Experience (UX) practitioners.

User Experience (UX) is how people interact with a brand, product, or service online and offline. UX designers ensure that the user perceives the product as functional and user- friendly (Aston, 2020). When user experience is good, companies experience increased sales, customer retention, market share, and other benefits. When user experience is terrible, conversions are decreased drastically (Willott, 2019).

UX method can maximize and improve the usability, accessibility, and success of a digital product, in this case website (Merritt \& Zhao, 2021). Sundberg (2015) explored the role of UX in B2B relationships from the customer companies and found that UX was not considered one of the most important impacts on supplier selection as previous experiences and supplier reputation can be a result of positive UX. The result also indicates that the pragmatic aspects (e.g., efficiency, reliability, ease-of-use) of technological products were still considered more important than the hedonic aspects (e.g., creativity, attractiveness, visual aesthetics).

However, a research conducted by Somia Customer Experience (2017) shows that startups dominated the distribution of the UX profession in Indonesia in 2017 with $51.6 \%$, but $57.8 \%$ of UX practitioners stated that their current companies have not fully acknowledged the importance of UX.

Based on the previous studies, it can be seen that even though UX has been widely known and applied, the core objective of UX itself was not appropriately implemented by the customer company. It then led to questions, which kind of company is ready for UX and what kind of particular UX service they currently and will need. Therefore, as a new UX 
studio, Uxgala is required to understand these questions by analyzing its market to conduct a service offering and marketing strategy that meets the target.

\section{B. Business Overview and Its Challenges}

Uxgala is a new UX development studio based in Bandung, Indonesia, which provides a wide range of UX services for a digital product, including product design and UX consultant: UX auditing and consultation, and UX training courses. Three UI/UX freelancers founded Uxgala with different UX specializations, namely UI/UX designer, UX researcher, and UX writer. The founders have the same vision that UX works in the digital product can be improved by involving the three mandatory skills - design, copywriting, and research - in a single project. This practice was well adapted by the unicorn startups in Indonesia, for instance, Tokopedia, Gojek, and Traveloka.

However, the practices were often simplified in the actual industry, with only a UX designer (even a graphic designer) to handle the whole project. Several reasons might cause it, for instance, the investment options-where the company felt the urge to invest more in other needs-a company's belief that UX is insignificant for their business that sometimes influenced by the unconsciousness regarding the importance of investing in UX for their business continuity. A minisurvey compiled by Uxgala's founders in the midst of 2020 , by collecting insights from clients of previous projects, and some collaborated projects with three software houses in Indonesia, found that 19 out of 31 business practitioners, or $61 \%$ of the total data, perceived UX design as an investment choice to make their digital product have an attractive visual. These perceptions led to decisions that if they could not do the task alone, they would hire UI/UX designer freelancers, even graphic designer freelancers.

The demand for UX development is rising alongside the vast digitalization in Indonesia. However, the data above illustrated that instead of the rising demand, the UX development business faces obstacles to compete in this B2B market. One of which is Uxgala. Uxgala as a new small player in the market is faced with many competitors and substitutes that can be the options for the market. Not to mention Uxgala's weak competitive advantage and low reputation as a newcomer.

The mixture in the market conditions makes Uxgala need to do a customer analysis to obtain information from the actual market towards their behavior, preferences, and buying decisions. Therefore, Uxgala can determine a specific market to target and develop a marketing strategy that suits the targeted market.

\section{Research Objectives}

The purpose of this research is to directly analyze the potential market using a business buying behavior framework, through customer analysis, to identify the target market for Uxgala and the target of each marketing activity. The findings will then examine to develop the marketing strategy, particularly the Targeting and Positioning strategy and 7P's Marketing Mix for Uxgala to fill the gap between the Uxgala condition and the actual market condition.

\section{LITERATURE REVIEW}

\section{A. Segmenting, Targeting, and Positioning (STP)}

All marketing strategy is built on segmentation, targeting, and positioning (STP). A company discovers different needs and groups of consumers in the marketplace, targets those it can satisfy most, and then sets its offerings. Market segmentation is an activity in defining market by dividing smaller groups with distinct needs, characteristics or behaviors which might separate products or marketing programs. Market targeting consists of evaluating each market segments attractiveness and selecting on or more market segments to enter. Meanwhile, positioning is explained as the product defined by consumers on important attributes (Kotler \& Armstrong, 2021). It demonstrates a product's perception, identity, and personality in the minds of customers. As a result, product positioning must be powerful.

\section{B. 7P's Marketing Mix}

The marketing mix is a collection of controllable variables of a firm, which are used by companies to pursue desired sales target (Kotler \& Armstrong, 2021). These are four variables: Product, Price, Place, and Promotion and made it into 4P's Marketing Mix. However, in service industry the 4Ps expanded to the 7Ps to address the different nature of service by adding People, Process, and Physical Evident elements into the traditional marketing mix (Booms \& Bitner, 1981).

\section{Business to Business (B2B) Marketing}

Business-to-business (B2B) marketing refers to marketing products or services to other businesses and organizations (Kearns, 2018). Before creating a maximum B2B marketing strategy, a firm need to understand the concept of the business market itself, which is different from the consumer market. Also, to understand the buying process or business buying behavior of the market.

The business demand is derived demand: it is ultimately come from (derives from) the demand for consumer goods. Furthermore, the main differences between business markets and consumer markets are the market structure and demand, the nature of the buying unit, and the types of decisions and the decision process involved (Kotler \& Armstrong, 2021).

\section{Business Buying Behavior}

Webster and Wind (1972) define organizational buying as the decision-making process by which formal organizations establish the need for purchased products and services and identify, evaluate, and choose among alternative brands and suppliers. Within the organization, buying activity consists of two major parts: the buying center, composed of all the people involved in the buying decision, and the buying decision process.

A buying center typically has five or six members and sometimes dozens. Some may be outside the organization, such as government officials, consultants, technical advisors, and other marketing channel members (Enright, 2006). Business buying decisions are influenced by an extremely complicated combination of environmental, interpersonal, and individual variables and an additional layer of organizational variables. 



Fig. 1. Major Influences in Business Buying Behavior (Kotler \& Armstrong, 2021).

The purchasing process in a business or organizational buying runs through several decision processes that contain steps, from the problem recognition by the buyers until the performance of supplier reviewed by the buyers. The process in each step can be different in accordance with the companies and the products.

\section{MethodOlOGY}

\section{A. Research Framework}

The customer analysis in this research used a business buying behavior framework that consists of two major sections: the buying center and the buying process. The objective of analyzing the buying center is to examine factors that influence the parties involved in the buying decision. The variable used to analyze the buying center is the five core customer and marketplace concepts by Kotler and Armstrong (2021): needs, wants and demands, market offerings, customer value and satisfaction, exchange relationship, and market. Meanwhile, analyzing the buying process aimed to examine the decision process, including the buying center/organizations' considerations, preferences, and objectives. The variable used is the stages of the business buying decision process which can be seen in Fig. 2 .



Fig. 2. Stages of Business Buying Decision Process (Robinson et al., 1967).

\section{B. Research Method}

The research method of this research is a customer analysis, using primary and secondary qualitative data. The primary data was obtained using direct interviews with the founder, owner, or the C-Level of a company. On the other hand, the secondary data was collected using indirect observation through social media and digital articles related to the respondents and their organizations.

The target population of this research was the companies that were included in the market segmentation of Uxgala, which consisted of startups in three sectors: E-Commerce, Online Service, and Tech/SaaS. that can be seen in Table I.

As for the sampling method, considering that the number of business market is much lesser than the consumer market, the minimum required sample is three respondents for each segment, with consideration that with five respondents, there will be no balanced results so that conclusions about sample preferences over the population are not ambiguous and can be clearly drawn.

TABLE I: ThE MARKET SEgMENTATION OF UXGALA

\begin{tabular}{cccc}
\hline \hline \multicolumn{3}{c}{ Demography } & \\
\hline Industry & E-Commerce (M1) & Online Service (M2) & Tech/SaaS (M3) \\
\hline Sector & $\begin{array}{c}\text { Marketplace, } \\
\text { Fashion, FnB }\end{array}$ & $\begin{array}{c}\text { Government, } \\
\text { Fintech, Health, } \\
\text { Transportation, } \\
\text { Education }\end{array}$ & $\begin{array}{c}\text { Analytic and } \\
\text { smart tools, } \\
\text { Travel, } \\
\text { Entertainment }\end{array}$ \\
\hline $\begin{array}{c}\text { Company } \\
\text { Size }\end{array}$ & Medium - large & Medium - large & Small - medium \\
\hline Location & $\begin{array}{c}\text { Capital cities in } \\
\text { Java, South } \\
\text { Sulawesi, and Bali }\end{array}$ & $\begin{array}{c}\text { Capital cities in Java, } \\
\text { South Sulawesi, and } \\
\text { Bali }\end{array}$ & $\begin{array}{c}\text { Jabodetabek and } \\
\text { Bandung }\end{array}$ \\
\hline Oechnology & Mobile app & Mobile app & $\begin{array}{c}\text { Website and } \\
\text { desktop app }\end{array}$ \\
\hline Market & B2B2C & B2C & B2B \\
\hline Users & Heavy users & Heavy users & $\begin{array}{c}\text { Light - medium } \\
\text { users }\end{array}$ \\
\hline \hline
\end{tabular}

\section{FINDING AND ANALYSIS}

\section{A. Customer Analysis Summary}

Based on the customer analysis conducted with a total of 18 respondents, including five respondents from the ECommerce (M1) market, eight respondents from the Online Service (M2) market, and five respondents from the $\mathrm{Tech} / \mathrm{SaaS}$ (M3) market, the result can be summarized as follow:

(1) The M1 and M3 segment demanded design and development services. The interview was focus on the mobile application as the digital product for M1 segment, and website/desktop application for the M3 segment. Both were dominated by the respondent who stated that they did not have the internal resource responsible to develop the digital product, made them entirely dependent on external parties to help them create technical requirements related to the digital product, which might also associate with their preference to choose a firm rather than a freelancer due to the complexity of the task. It also indicated that the decision or the preference about the service would directly involve the CEO or the CLevel in the company. It was related that both markets needed service providers who could perform a customer understanding and also understand their business, instead of the technical aspect only. M1 and M3 segment tend to broadcast the requirement information to the community platform or on their official website and social media, also very concerned with the timeline scheduling of the project realization.

(2) Meanwhile, M2 is the market that demands UX consultant service. In contrast with M1 and M3, the M2 segment has its internal resource to handle the digital product, in this case mobile application. It relates to their demand for 
simple to regular tasks, and therefore they preferred freelancers as the supplier to handle the mobile application requirements. Consequently, the supplier will have a lot of contact with the division that understands the technical aspect. In addition, the M2 segment also broadcasts their required information for supplier searching and selecting them by considering the portfolio. However, based on their experiences working with freelancers, they have challenged professionalism issues related to on-time service delivery. They were also influenced by external input, for instance, the new trends, or even the offers they received through email newsletter or exhibitions.

Table II simplified the mapping of the respondents' answers according to the market, and the demanded services: product design and development (P1), UX consultant (P2).

TABLE II: DATA DISTRIBUTION OF RESPONDENTS' ANSWERS

\begin{tabular}{|c|c|c|c|}
\hline & \multicolumn{2}{|c|}{ P1 } & \multirow{2}{*}{$\begin{array}{c}\text { P2 } \\
\text { M2 (Online Service) }\end{array}$} \\
\hline & M1 (E-Commerce) & M3 (Tech/SaaS) & \\
\hline \multicolumn{4}{|c|}{ Buying Center } \\
\hline $\begin{array}{l}\text { Competitive advantage and } \\
\text { digital platform }\end{array}$ & Essential & Insignificant & Essential \\
\hline Human resources & No internal resource & No internal resource & Own internal resource \\
\hline Needs, wants, and demands & Design and development & Design and development & Consultant \\
\hline Market offerings & UX Firm & UX Firm & Freelancers \\
\hline Value satisfaction & Service quality & Professionalism & Professionalism \\
\hline \multicolumn{4}{|c|}{ Business Buying Decision } \\
\hline Problem recognition & External & User & External \\
\hline General need description & Open for addition & Open for addition & Open for addition \\
\hline Product specification & External involvement & Internal/external involvement & Internal involvement \\
\hline Supplier search & Broadcast info & Broadcast info & Broadcast info \\
\hline Proposal solicitation & Accessible & Informative & Informative \\
\hline Supplier selection & Customer understanding & Customer understanding & Portfolio \\
\hline Order-routine specification & On time service & On time service & On time service \\
\hline Performance review & Find new & Find new & Find new \\
\hline
\end{tabular}

TABLE III: PROPOSED MARKETING STRATEGY FOR UXGALA

\begin{tabular}{|c|c|c|}
\hline Positioning & \multicolumn{2}{|c|}{ Strengthen Uxgala positioning as a user and business-oriented UX development service } \\
\hline Marketing Mix & $\mathrm{P} 1$-> M1, M3 & $\mathrm{P} 2->\mathrm{M} 2$ \\
\hline Product & Making software development as one of the main servic & \\
\hline \multirow[t]{2}{*}{ Price } & Developing pricing strategy to give flexibility for custo & \\
\hline & Retained payment method & Bundling pricing \\
\hline \multirow[t]{2}{*}{ Place } & Maximizing social media and community platform: & \\
\hline & $\begin{array}{l}\text { - Micro-blogging social media } \\
\text { - Messaging application for communities }\end{array}$ & $\begin{array}{l}\text { - Portfolio showcasing social media } \\
\text { - Creative feature sharing community }\end{array}$ \\
\hline Promotion & $\begin{array}{l}\text { - Participate in startup and design/tech event } \\
\text { - Publishing educational or informative articles about } \\
\text { business and UX }\end{array}$ & $\begin{array}{l}\text { Collecting and creating design kit or UX design } \\
\text { tools to share as a freemium content }\end{array}$ \\
\hline Physical Evidence & \multicolumn{2}{|l|}{ Forming the UX case studies to use as portfolios } \\
\hline People & Hiring UI/UX designer and researcher & Hiring content creator and copywriter freelancers to maximize the SEO, blogging, and content creation \\
\hline Process & \multicolumn{2}{|c|}{$\begin{array}{l}\text { Improving the process to deliver a business-oriented service } \\
\text { Adapting the use of technology to maximize the remote working }\end{array}$} \\
\hline
\end{tabular}

\section{B. Proposed Marketing Strategy}

Based on the customer analysis, the author found that the market had a demand for specific UX services, that they wanted it to be more business oriented. While at the same time, the people in Uxgala can deliver that demanded service. Therefore, Uxgala must improve and strengthen its positioning strategy as a business oriented UX development to distinguish it from the competitors and accentuate its competitive advantages.

The segment will be categorized according to the product/service offered. The first is UI/UX design and development (P1), which targets the E-Commerce market (M1), and Tech/SaaS market (M3). Then the second one is product UX Consultant (P2), which is primarily offered for the Online Service market (M2). Noted that the result of the customer analysis showed that different markets required different products, and the behavior will tend to be different too. Table III shows the categorized proposed marketing strategy.

\section{CONCLUSION AND DISCUSSION}

\section{A. Conclusion}

The purpose of this research was to develop a B2B marketing strategy for Uxgala, a newcomer User Experience (UX) Studio, to fill the gap between the company's condition that had weak competitive advantages among the competitors and substitutes, and the market condition which was rising the demand for UX development service. The marketing strategy in this research was focused on the STP strategy and 7P's Marketing Mix. In order to develop the marketing strategy itself, the author analyzed the customer using the business buying behavior framework, which consists of analyzing the buying center and the purchasing decision process.

The customer analysis was carried out using direct interviews and indirect observations on respondents' companies' social media and digital articles related to the respondent and the company. The result showed that different markets have different needs for UX development services. 
Therefore, after categorizing the results and analyzing the behavior of each market, the authors conclude that:

1) Uxgala can better serve the E-Commerce market and the Technology/SaaS market with design and development services. Meanwhile, the Online Service market will be targeted for UX consulting services.

2) Uxgala must strengthen its positioning as a UX development company that provides UX services with a user and business approach. Based on customer analysis, respondents stated that they demand a UX service provider who can understand the business-driven behind the design decision and understand the product as much as the user.

3) The proposed 7P's marketing mix for Uxgala was divided into two strategies. First, the strategy for product, physical evidence, people, and process, can be implemented by Uxgala in general. Meanwhile, price, place, and promotion, that the realization will be different according to the service and each targeted market. Therefore, Uxgala can have a clear guidance to actualize a marketing activity based on the marketing objectives.

\section{B. Discussion}

The UX and customer value have been widely studied in the $\mathrm{B} 2 \mathrm{C}$ context, as well as in the B2B context, understanding the phenomenon of UX in B2B-relationship and understanding its role in different supplier and customer activities (Merritt \& Zhao, 2021; Sundberg, 2015). However, the value of experience in the point of view of UX service provider, as a supplier in the B2B market, has still remained relatively unexplored. This study contributes to the research streams of UX, by exploring the B2B market in UX phenomenon, and UX business in the digital product industry, particularly in Indonesia.

One issue that should be taken into consideration is the time limitation. The case study for this research using a newcomer UX studio, which still lack of marketing activities. $\mathrm{n}$ order to analyze the further impact of this research, it will be better to have the before and after data. In order to avoid this limitation, more longitudinal studies should be conducted considering the implementation of marketing activities can take a long period of time.

\section{REFERENCES}

App Annie. (2021). State of Mobile 2021. https://www.appannie.com/en/go/state-of-mobile-2021/

Aston, B. (2020). 15 Statistics You Should Know About A Career In UX Design. $\quad$ https://thecxlead.com/general/statistics-about-career-in-uxdesign/.

Booms, B. H., \& Bitner, M. J. (1981). Marketing Strategies and Organizational Structures foro Service Firms. Marketing of Services.

Daily Social. (2020). Startup Report 2020: Business Resiliency during the Pandemic. 55958, 50.

Enright, A. (2006). It Takes a Committee to Buy into B-to-B. Marketing News, 12-13.

Kearns, S. (2018). What is B2B Marketing: Definition, Strategy, and Trends. https://www.linkedin.com/business/marketing/blog/contentmarketing/what-is-b2b-marketing-definition-strategy-and-trends

Kotler, P., \& Armstrong, G. (2021). Principles of Marketing (P. Kotler \& G. Armstrong (eds.); 18th ed.). Pearson.

Merritt, K., \& Zhao, S. (2021). An innovative reflection based on critically applying ux design principles. Journal of Open Innovation: Technology, Market, and Complexity, 7(2). https://doi.org/10.3390/joitmc7020129.

Robinson, P. J., Faris, C. W., \& Wind, Y. (1967). Industrial Buying and Creative Marketing. Allyn \& Bacon.
Somia Customer Experience. (2017). The State of UX Profession in Indonesia. https://www.somiacx.com.

Startup Genome. (2021). The Global Startup Ecosystem Report GSER 2021. 290. https://startupgenome.com/reports/gser2021.

Sundberg, H.-R. (2015). The role of user experience in a business-tobusiness context. In Tampere University of Technology. Publication (Vol. 1278, Issue 2015).

Webster, F. E., \& Wind, Y. (1972). Organizational Buying Behavior. Prentice-Hall.

Willott, L. (2019). Customer Service Stats for 2020. https://www.customerthermometer.com/customer-service/customerservice-and-satisfaction-statistics-for-2020/.

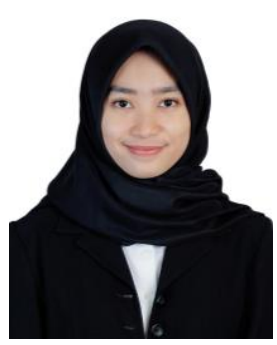

Siti Khumaerah Mufti, S.T. was born on April 29th 1996 in Makassar, Indonesia. Graduated from Informatics Engineering at Hasanuddin University Makassar in 2018. She pursued her master degree in Master of Business Administration at Bandung Institute of Technology, focusing in cultural and creative entrepreneurship program. Currently, her major interest is in entrepreneurship, particularly related in the digital product and startup industry.

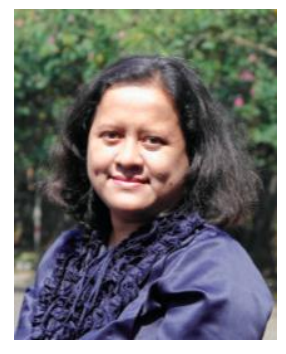

Atik Aprianingsih, S.T, MM, DBA. is a lecturer and researcher in Business Strategy and Marketing Interest Group, and a Director of Research and Knowledge Unit of the School of Business and Management at Bandung Institute of Technology, Indonesia. She completed her doctorate in business administration at Saint Ambrose University in Davenport, Iowa, USA in 2012. Dr. Aprianingsih expertise and research interest is in strategic management, technology adoption, and behavioral studies. 